\title{
Grisel Syndrome: Prompt Diagnosis, Prompt Management Equals Happy Ending
}

Aidi Aswadi Halim Lim ${ }^{1}$, Azian Abdul Aziz ${ }^{1}$, Ahmad Razali Md Ralib ${ }^{1}$

${ }^{1}$ Department of Radiology, Kulliyyah of Medicine, International Islamic University of Malaysia

Presenter: Aidi Aswadi Halim Lim

Grisel syndrome is a rare cause of torticollis resulting from subluxation of the atlanto-axial joint (C1-C2 vertebra) joint from surrounding soft tissue inflammation. Atlanto-axial joint injuries typically occur in the setting of trauma. However, here we report a case of a non-traumatic cause of atlanto-axial joint subluxation in a child. The child initially presented to our centre with 5 days history of torticollis preceded by a few days of upper respiratory tract symptoms. The initial radiograph of the cervical spine did not demonstrate any obvious abnormality. However, due to a high index of suspicion by the attending physician, a CT of the cervical spine was performed, which indeed revealed an atlanto-axial subluxation. The patient was put on cervical traction for a few days, and discharged well with soft collar and analgesia. 